\title{
Measurement of Low Order Ductility
}

by Norman P. Pinto

$I^{N}$ $\mathbf{N}$ the determination of the mechanical propertles of metals, an evaluation of the ductility is essential for a complete description of engineering properties. Standard methods are entirely adequate for measuring the ductility of most metals, 1.e., the relatively ductile metals. The low orders of ductllity, however, are more difflcult to measure and revisions of methods and techniques are required to obtain accuracy, which is usually more important for brittle metals. The measurement method described here has been used successfully for beryllium and tungsten specimens.

Ductility is evaluated by measuring the elongation of the outer flbers of a test specimen during tension and by computing the degree to which a specimen will contract before rupture. Compression tests, or upsetting tests, are usually applied only to very malleable metals. In the case of metals which deform only slightly, the reduction in cross-sectional area is particularly and restrictively difflcult to measure, as is the calculation for elongation of metals which rupture without deforming plastically.

Measurements of the ductility of beryllium have been limited, since the metal in its present state of development is characterized by low ductility, which is less than 10 pct and often about 1 pct for elongation in 2 in. The use of a lever-type strain gauge during the development of metallurgical processes, such as powder metallurgy methods, is impractical due to the danger of breakage. It has been found, however, that specimens of brittle metals may be bent around radii of $13 / 4$ to 6 in. It appears then, that a feasible method for ductility testing would be the bending of a bar over mandrels of successively smaller radil. A simplification of such a procedure would be the bending of a bar over a form, such as that in Fig. 1, in which the radius of curvature decreases progressively. Radii at each point are predetermined and elongation is read from a graph of radius of curvature at point of fracture versus known bar thickness, Fig. 2. In use, the test bar is bent by rolling it around the form with manual force normal to the curved surface; a flat metal bar is most useful for applying this force.

This test provides a value of elongation for the outer fibers of the test specimen at the point of

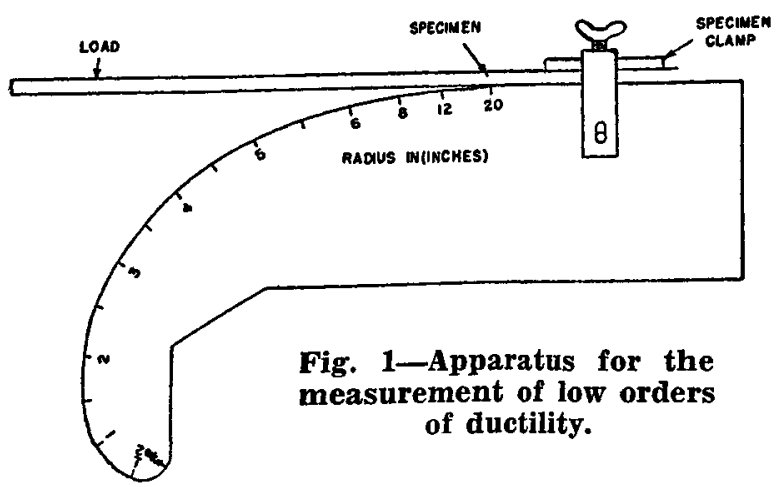

iracture. Whereas a simple beam test gives a measure of deformation (a radius of curvature determined by three points) only within the elastic range, this bend test is valid through both elastic and plastic ranges. Only the fibers on one

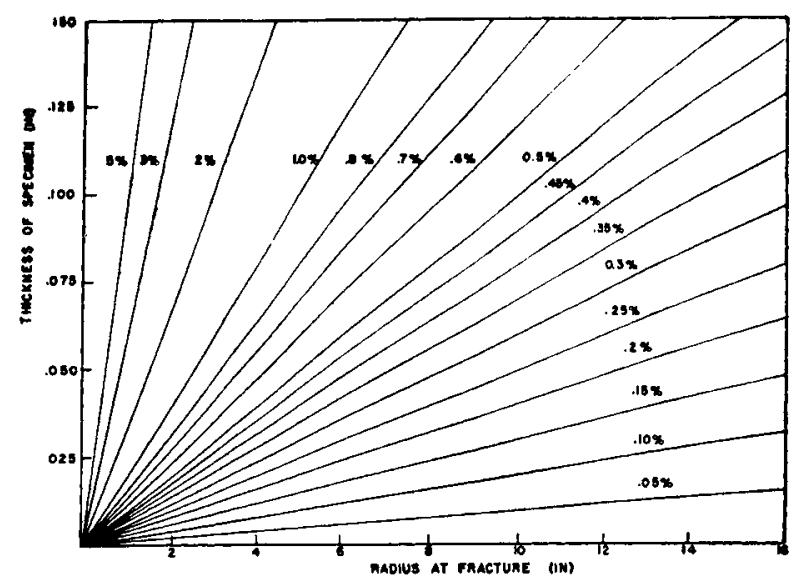

Fig 2-Graph for determining elongation from known specimen thickness and radius at fracture.

side of a specimen are in tension, and the problem of premature failure at a notch is less than with the axially loaded tensile test. The preparation of specimens is particularly simple, and round, square, or rectangular samples may be employed. Surface finish is not as critical as it is in the torsion test. Inasmuch as only a fraction of the surface of the specimen is tested at the fracture radius, the test should be checked on a second specimen. As with all other mechanical tests, the condition of the bend test, e.g., rate of load application, test temperature, must be defined.

The simplicity of the design and ease of construction are definite advantages for this method of testing low orders of ductility; the specimen clamp may be eliminated by securing the form and specimen between the smooth jaws of a vise. The scale and proportions are, of course, arbitrary and should be selected to accommodate a particular range. The range illustrated has proven useful in the testing of beryllium and tungsten.

It should be noted that this test does not yield precise values of elongation but approximations useful particularly in comparing similar materials. The complex changes within a specimen during plastic deformation are functions of the mechanical properties of the particular metal, and although minimized by the small geometrical changes in this test, are significant in arriving at a definite value for elongation.

Norman $P$. Pinto is Metallurgist at the Metallurgical Labs of Sylvania Electric Products Inc., Bayside, $N . Y$. 